\title{
CORRELATES OF FOOD INSECURITY AMONG UNDERGRADUATE STUDENTS
}

\author{
CASEY HAMLION \\ UNIVERSITY OF \\ BRITISH COLUMBIA
}

\author{
DARLENE TAYLOR \\ UNIVERSITY OF \\ BRITISH COLUMBIA
}

\author{
ANNE HUISKEN \\ UNIVERSITY OF \\ BRITISH COLUMBIA
}

\author{
JOAN L. BOTTORFF \\ UNIVERSITY OF \\ BRITISH COLUMBIA
}

\begin{abstract}
Food insecurity has been identified as an issue among postsecondary students. We conducted this study to describe the level of food insecurity in a sample of university students with a particular interest in the effect of marginalization. A cross-sectional survey was conducted using a volunteer sample of 3,490 undergraduate students ( $44 \%$ participation rate) at one BC university campus between February and May 2017. Experiences of food insecurity were reported by $42.3 \%(n=1,479)$ of respondents. Among those who were food insecure $60.2 \%(n=891)$ were female. Logistic regression analysis indicated that females, students living on campus, those with a diversability (developmental, physical, or other disability), individuals self-reporting as belonging to a visible minority, and international students were more likely to experience food insecurity than comparator groups. When adjusted for gender, years on campus, and living situation, students who reported experiencing two or more forms of marginalization were 2.52 times more likely to be food insecure compared to students who do not report any form of marginalization. This study further supports concerns about high levels of food insecurity among university students in Canada. In particular, the findings highlight the risk for food insecurity among students who are already vulnerable to socio-economic inequity due to belonging to marginalized groups. Efforts to promote student well-being on university campuses need to address food insecurity by addressing system-level factors to equalize the field for all students at risk for food insecurity. Keywords: food deprivation, hunger, vulnerable populations, gender, higher education
\end{abstract}

\section{Résumé}

L'insécurité alimentaire est un problème chez les étudiants de niveau postsecondaire. Notre étude décrit le degré d'insécurité alimentaire parmi un échantillon d'étudiants postsecondaires, en portant un intérêt particulier aux effets de la marginalisation. Une étude transversale a été réalisée à l'aide d'un échantillon composé de volontaires, soit 3490 étudiants universitaires au premier cycle dans une université de Colombie-Britannique (taux de participation de $44 \%$ ) entre février et mai 2017. Quarante-deux pour cent $(n=1479)$ des répondants étaient considérés comme étant en situation d'insécurité alimentaire. Parmi eux, $60.2 \%$ ( $n=891)$ étaient des femmes. Une analyse de régression logistique a indiqué que les femmes, les étudiants qui vivent sur le campus, ceux qui ont des compétences cognitives, neurologiques, physiques ou développementales diversifiées, ceux qui font partie d'une minorité visible et les étudiants internationaux étaient plus susceptibles de connaitre l'insécurité alimentaire que ceux des groupes de comparaison. Quand on prend en compte le genre, les années passées sur le campus et les conditions de vie, les étudiants qui s'identifiaient à deux catégories de marginalisation ou plus étaient 2,52 fois plus susceptibles de souffrir de l'insécurité alimentaire que les étudiants qui ne s'identifiaient à aucune catégorie de marginalisation. Cette étude souligne davantage les défis de la grande insécurité alimentaire parmi les étudiants de niveau postsecondaire au Canada. En particulier, les résultats de cette étude soulignent le risque d'insécurité alimentaire parmi les étudiants qui sont déjà vulnérables aux inégalités socioéconomiques à cause de leur appartenance à des groupes marginalisés. Les efforts déployés pour la promotion du bien-être des étudiants universitaires doivent aborder plusieurs facteurs systémiques de manière à égaliser le terrain pour tous les étudiants susceptibles de souffrir de l'insécurité alimentaire.

Mots-clés : insécurité alimentaire, faim, groupes vulnérables, genre, éducation supérieure 


\section{Introduction}

Household food insecurity affects more than 3.2 million people in the Canadian population and has serious health and social impacts (Tarasuk et al., 2016). The Government of Canada (2012a, para 1) defines household food insecurity as "the inability to acquire or consume an adequate diet quality or sufficient quantity of food in socially acceptable ways, or the uncertainty that one will be able to do so." Despite variations in definitions and measures used to describe food insecurity among postsecondary students, studies consistently show that a substantial portion of students experience some form of food insecurity. Furthermore, a recent systematic review of 59 studies concluded that university students experience higher rates of food insecurity than the general population (Bruening et al., 2017). Among Canadian campuses, $39 \%$ of students were found to experience some degree of food insecurity, although patterns of food insecurity varied by province and institution (Silverthorn, 2016). Living with food insecurity influences student physical and emotional well-being and contributes to adverse academic outcomes (Bruening et al., 2017; Farahbakhsh et al., 2017; Silva et al., 2017). Understanding the correlates of food insecurity among students is an important step towards informing policy approaches to improving the food security status of individuals attempting to improve their lives through higher education.

Silverthorn (2016) reported that Aboriginal and racialized peoples, off campus dwellers and students that primarily funded their education through government student financial programs had higher rates of food insecurity. Students mainly attributed their food insecurity to the high cost of food, tuition fees and housing costs. Other research shows that international students are more likely to experience food insecurity than their national counterparts (Entz et al., 2017). Similarly, a study examining food insecurity among small and rural Canadian universities found that students in higher years of study and those who lived off campus had higher rates of food insecurity (Reynolds et al., 2018).

As part of a campus-wide survey to gather student views about system-level factors that influenced mental well-being, we included a question on worry about running out of food. Others have reported that students experience persistent worry about not having enough money for food (Frank, 2018). Financial constraints are also commonly considered in defining adequate access to food. For example, marginal food security as defined by Research to Identify Policy Options to Reduce Food Insecurity (PROOF) (2018) includes worry about running out of food due to a lack of money for food. The data we collected in our well-being survey, therefore, provided the opportunity to examine food security among undergraduate students and its associated socio-demographic factors with a particular interest in the effect of marginalization. The research objectives were to: 1 ) describe the proportion of students experiencing food insecurity on a BC university campus, and 2) determine demographic correlates of food insecurity among university students. This study was approved by the University of British Columbia Behavioural Ethics Review Board (H16-01785).

\section{Methods}

\section{Study Design}

A study using a cross-sectional survey design was conducted in order to collect data related to system-level factors (social, cultural, physical, academic, economic, and policy) that influence student mental well-being on one $\mathrm{BC}$ university campus with an enrolment of approximately 10,000 students. Data were collected between February and May 2017 using a self-administered questionnaire available in paper and in electronic form using the Qualtrics survey tool. Paper-based data were entered into the online survey using unique identifiers by trained research assistants to ensure data quality. Data were cleaned for errors and outliers. This paper reports a sub-analysis using data collected on food insecurity and socio-demographics among undergraduate respondents.

\section{Sampling Method}

A volunteer sampling approach was used. Students were recruited through posters that were displayed throughout the campus and through in-person invitations by surveyors who walked around campus with paper-based surveys. The posters provided a URL for students to access an electronic version of the survey. This URL was also made available on a campus Facebook page. Finally, surveyors were given permission to invite students to complete the paper-based survey during class time. 
Classrooms were selected to ensure representation from different various faculties and degree offerings (BSN, BSc etc.). In all recruitment approaches, students were invited to share their views on system-level factors on campus that influenced student mental well-being. There was no mention of food insecurity or any effort to purposefully recruit food insecure students. Completion of the survey implied consent to participate in this research. There were no exclusion criteria.

\section{Measures}

Food insecurity was assessed using a single question that asked: "In the past 12 months, have you worried that food would run out before you got money to buy more food?" This is an adapted question from the food insecurity question series used in the Household Food Security Survey Module (HFSSM) (Government of Canada, 2012b). We removed reference to "others" worrying about running out of food from the question. Possible response options included often, sometimes and never. For this analysis, responses were collapsed into two categories: Food Secure (those who responded never) and Food Insecure (those who responded sometimes or often). There is research that supports that even one affirmative answer on the FHSSM indicates heightened vulnerability to adverse health outcomes associated with food insecurity, and can be used to classify respondents as experiencing marginal food insecurity (PROOF, 2018). Although these questions have not been validated for individuals, they have been used in the 2014 Canadian Community Health Survey (Question FSC_Q020).

Socio-demographic questions were included. Gender was assessed using the question: Do you identify as male, female, transgender, or other. In addition, we included questions to assess type of student (undergraduate/graduate), length of time on campus (less than 1 year, 1-2 years, 3-4 years, and 5 or more years), and place of residence (off campus/on campus). To assess potential for experiences related to marginalization we asked students if they identified with any of the following groups: LGBTTQIA+ (to represent the diversity of sexual orientations and gender identity-based cultures), Aboriginal (First Nations, Metis, Inuit), international student, and visible minority. Multiple answers were permitted. In addition, the presence of diversabilities (Steinprinz, 2017) was assessed by asking: Are you a person with a developmental, physical, or other diversability (yes/nol prefer not to answer)? Although a definition of diversability was not included in the survey, we used this concept to recognize the highly diverse nature of the limitations that challenge students with disabilities and as well as their diverse abilities.

\section{Analysis}

Frequency analyses were conducted to describe food insecurity and demographics. Bivariate analyses, using Chi Square tests, were used to determine if there was an association between food insecurity and socio-demographic variables of interest. With gender and living situation (on/off campus) as control variables, binary logistic regression models were conducted to determine the adjusted and unadjusted odds of being food insecure when students reported experiences of marginalization. Significant indicators of marginalization (LGBTTQIAt, International Student, visible minority) were included in addition to Aboriginal. Although the Aboriginal variable was not a significant indicator, we included it in the regression model because of marginalization experiences within this group. An alpha level of $<0.05$ was deemed significant. An Ominibus test of model coefficients and a Hosmer and Lemeshow test were conducted to test for goodness of fit of the logistic regression model. Variables tested for multicollinearity using tolerance and the variance of inflation factor (VIF) diagnostics included the indicators of marginalization where multiple answers were permitted (LGBTTQIA+, Aboriginal, International Student, visible minority). Post-estimation predicted probabilities were also calculated. All analyses were performed using the statistical package SAS 9.4.

\section{Results}

A total of 3490 undergraduate students were included in the study. Based on the number of undergraduate students at enrolment $(n=7930)$, the response rate was $44 \%$. Compared to available 2016-2017 university enrollment statistics, survey respondents were representative of the undergraduate campus population related to: gender (female study sample $57.1 \%$ vs undergraduate population $54 \%$ ); living on campus (study sample $22.6 \%$ vs undergraduate population 19\%); and identifying as Aboriginal (study sample $5 \%$ vs undergraduate population $5 \%$ ) or an international student (study sample $13.4 \%$ vs under- 
Table 1. Socio-demographics of all respondents, and characteristics of the study sample by food security status (n, \%)

\begin{tabular}{lllll}
\hline & $\begin{array}{l}\text { All respondents } \\
(n=3490)\end{array}$ & $\begin{array}{l}\text { Food Secure } \\
(n=2011) \\
57.7 \%\end{array}$ & $\begin{array}{l}\text { Food Insecure } \\
(n=1479) \\
42.3 \%\end{array}$ & Sig \\
\hline Gender identity & & & \\
Male & $1412(40.5 \%)$ & $863(42.9 \%)$ & $549(37.1 \%)$ & $p<.05$ \\
Female & $1994(57.1)$ & $1103(54.8 \%)$ & $891(60.2 \%)$ & \\
Transgender/Other & $20(0.6)$ & $11(0.5 \%)$ & $9(0.6 \%)$ & \\
Prefer not to answer/Missing & $64(1.8)$ & $34(1.7 \%)$ & $30(2.0 \%)$ & \\
\hline Lives on campus & $788(22.6 \%)$ & $416(20.7 \%)$ & $372(25.2 \%)$ & $p<.01$ \\
\hline Experiences of marginalization & & & & \\
\hline Has a diversability & $232(6.6 \%)$ & $98(4.9 \%)$ & $134(9.1 \%)$ & $p<.001$ \\
\hline Identifies as LGBTTQIA+ & $202(5.8 \%)$ & $103(5.1 \%)$ & $99(6.7 \%)$ & $p<.05$ \\
\hline Identifies as Aboriginal & $175(5 \%)$ & $95(4.7 \%)$ & $80(5.4 \%)$ & \\
\hline Identifies as international student & $406(13.4 \%)$ & $203(10.1 \%)$ & $203(13.7 \%)$ & $p<.001$ \\
\hline Identifies as visible minority & $467(13.4 \%)$ & $238(11.8 \%)$ & $229(15.5 \%)$ & $p<.01$ \\
\hline
\end{tabular}

graduate population $12 \%)$. The majority of respondents (95\%) completed the paper-based survey.

Forty-two percent $(n=1479)$ of our undergraduate sample were classified as experiencing food insecurity. Although the majority of food insecure students reported that they 'sometimes worried' that food would run out before they got money to buy more $(n=1084,73.3 \%)$ more than one fourth of the students reported they 'often worried' about this scenario $(n=395,26.7 \%)$. Among those who were food insecure, $60.2 \%(n=891)$ identified as female, $37.1 \%(n=549)$ as male, $0.6 \%(n=9)$, as transgender or other, and the remaining $2 \%$ were classified as missing and prefer not to answer $(n=30)$. Table 1 displays the characteristics of the study sample and between group comparisons based on food security status.

Results of the regression analysis indicated that students identifying as female, those living on campus, those with a diversability, individuals self-reporting as belonging to a visible minority, and international students were more likely to experience food insecurity. Particularly noteworthy is the finding that students with diversability traits were 1.89 times more likely to experience food insecurity than those who didn't report having diversability traits (Table 2). When adjusted for gender, years on campus, and living situation, students who reported experiencing two or more forms of marginal- ization are 2.50 times (95\% Cl 1.81-3.46; $p<.001)$ more likely to be food insecure compared to students who did not report any form of marginalization. The Omnibus test and the Hosmer and Lemeshow test revealed excellent goodness of fit $(p<.001, p=0.786$ respectively). Multicollinearity was not detected among marginalization variables (tolerance scores $=0.1$ and $\mathrm{VIF}=1$ ) or between gender and LGBTTQIA+ (tolerance scores $=0.1$ and $\mathrm{VIF}=1$ ).

The results of the predicted probabilities analysis indicated that students who experience forms of marginalization are more likely to experience food insecurity than those who do not experience forms of marginalization (Table 3).

\section{Discussion}

The purpose of this analysis was to determine demographic correlates of food insecurity among university students with a particular interest in the effect of marginalization. Our findings show that a large portion (42\%) of undergraduate students are worried about running out of food before they get more money to buy more. Although the findings cannot be generalized to other campuses, the prevalence of food insecurity among our study population is consistent with other studies (Bruening et al., 
Table 2. Correlates of food insecurity among undergraduate students

\begin{tabular}{lll}
\hline & Unadjusted odds $(95 \% \mathrm{Cl})$ & Adjusted odds $(95 \% \mathrm{Cl})$ \\
\hline Male & REF & REF \\
Female & $1.27(1.11-1.46)^{* * *}$ & $1.33(1.15-1.53)^{* *}$ \\
Transgender/Other & $1.29(0.53-3.12)$ & $0.90(0.35-2.30)$ \\
Prefer not to answer & $1.38(0.84-2.29)$ & $1.475(0.88-2.66)$ \\
\hline Off campus & REF & REF \\
On campus & $1.29(1.10-1.51)^{* *}$ & $1.29(1.09-1.53)^{* * *}$ \\
\hline Experiences of Marginalization & REF $=$ NO & REF= NO \\
Has a Diversibility & $1.95(1.49-2.55)^{* *}$ & $1.89(1.44-2.49)^{* *}$ \\
Identifies as LGBTTQIA+ & $1.33(1.00-1.76)^{*}$ & $1.27(0.94-1.71)$ \\
Identifies as Aboriginal & $1.15(0.85-1.57)$ & $1.24(0.90-1.69)$ \\
Identifies as international student & $1.41(1.15-1.74)^{* * *}$ & $1.38(1.12-1.72)^{* * *}$ \\
Identifies as visible minority & $1.37(1.12-1.66)^{* *}$ & $1.39(1.12-1.72)^{* * *}$ \\
\hline${ }^{*} p<.05$ & & \\
${ }^{* *} p<.01$ & &
\end{tabular}

Table 3. Predicted probabilities of undergraduate students experiencing marginalization and being food insecure

\begin{tabular}{l|l|l|l}
\hline Experiences of Marginalization & Predicted probability & Standard error & Sig \\
\hline Diversibility & & & \\
Yes & 0.77 & 0.20 & $p<.001$ \\
No & 0.12 & 0.17 & \\
\hline LGBTTQIA+ & & & \\
Yes & 0.57 & 0.22 & $p<.01$ \\
No & 0.33 & 0.18 & \\
\hline Aboriginal & & & $p<.05$ \\
Yes & 0.54 & 0.22 & \\
No & 0.34 & 0.16 & $p<.001$ \\
\hline International Student & & & \\
Yes & 0.60 & 0.19 & \\
No & 0.28 & 0.17 & $p<.001$ \\
\hline Visible Minority & & 0.19 & \\
Yes & 0.61 & 0.17 & \\
No & 0.28 & & \\
\hline
\end{tabular}


2017; Silverthorn, 2016) indicating that food insecurity remains a problem among postsecondary students. Postsecondary students represent an important group experiencing food insecurity. Yet, they are frequently not identified as vulnerable to food insecurity in the general population and not a focus of attention in national level initiatives or policies to advance food security.

On examination of student characteristics associated with food insecurity, some of our findings were found to be consistent with previous research and some were not. Those that were consistent included covariates such as being an international student, which placed individuals at higher risk of experiencing food insecurity compared to Canadian students (Hanbazaza et al., 2017). Our finding that students identifying as female are at higher risk for food insecurity than their male peers is also consistent with several other studies (Maroto et al., 2015; Spaid \& Gillett-Karam, 2018).

Our study revealed that students living on campus were at higher risk of experiencing food insecurity than those living off campus. Other studies have also shown that living locations and situations influence student food insecurity. For example, some studies show that students living off campus are at higher risk than those living on campus (Blundell et al., 2018; Reynolds et al., 2018; Silverthorn, 2016), with students at highest risk being those who live alone or are single parents. When students are living off campus with parents, they are less likely to report food insecurity (Bruening et al., 2017). Nevertheless, the risk for food insecurity for students living on campus is a concern given that the majority of these students were required to purchase meal plans. Others have also reported food insecurity among students with meal plans (Broton et al., 2018), including those that have meals left in their meal plans (Van Woerden, 2019). Our data were collected in the second semester of the academic year, so it is possible that students on a meal plan were worried about whether they had enough money left in their plan to carry them through to the end of term (Zuercher \& Lutz, 2018). Furthermore, the campus on which this study was conducted is situated in an area of the community where there are no grocers and limited food amenities, reducing students' access to more affordable food options. We need to improve our understanding of contextual factors related to living arrangements that influence students' access to healthy food. In addition, our adjusted analysis did not show higher rates of food insecurity among students identifying as Aboriginal unlike other studies which found Aboriginals and racialized students to be at higher risk of experiencing food insecurity (Silverthorn, 2016). More research is required to understand the reasons for our disparate results.

Although others have reported that university students who experience marginalization due to being a visible minority based on racial/ethnic background are vulnerable to food insecurity (e.g., Broton et al., 2018; Silverthorn, 2016), our study findings draw attention to students experiencing other forms of marginalization such as identifying as LGBTTQIA+ or having diversability traits and their vulnerability to experiencing food insecurity. These findings are supported by food security research that indicates inequities within the North American food system among groups of people of colour, from the LGBTTQIA+ community, and those who have a diversability (Billings \& Cabbil 2011; Brown et al., 2016; Brucker, 2016). Our findings indicate that the risk of food insecurity is highest among those who experience more than one form of marginalization. The impact of food insecurity on academic achievement may further socio-economic inequities among groups of students who may experience vulnerabilities related to marginalization.

Food insecurity has been linked to low income which hinders students' ability to pay for food, tuition and housing (Silverthorn, 2016). Low income forces students to make compromises on how they spend their money. Although tuition and housing are fixed costs, food is an elastic expenditure. Students who do not have enough income, therefore, are forced to compromise the quality and quantity of food they purchase (Maynard et al., 2018). The few studies describing the lived experiences of students making these difficult choices highlight resulting feelings of worry, stress and shame, and the impact on health and well-being as well as ability to focus on academics (Frank, 2018; Hattangadi et al., 2019; Maynard et al., 2018; Meza et al., 2019). How experiences of marginalization add further complexity to these choices and the impact of food insecurity on health and well-being has not been fully explored.

Given that food insecurity is closely related to markers of socioeconomic status, future research should focus on more in depth exploration of where students obtain their income (parents, student loans, employment), how often they run out of food and the other cost pres- 
sures that high risk students experience. Furthermore, an exploration of how structural factors such as mandatory food programs for students living on campus and policies that limit the number of hours a student can be employed on campus, contribute to food insecurity and nutritional inequity is needed. Efforts toward distributive justice should be made to equalize the playing field for vulnerable groups.

\section{Limitations}

This was a sub-analysis of data that were collected for the purpose of examining mental well-being to guide enhancement of campus health promotion approaches. Only one question related to food insecurity was asked, rather than a range of questions typically asked in other studies, and therefore important nuances related to factors influencing food insecurity may have been missed. There is a need to develop validated scales to assess individual food insecurity that are appropriate to typical post-secondary student populations and living arrangements. In addition, there are limitations to the use of un-validated questions to gather data on marginalization as well as diversability. Further research is needed to better understand the relationships among these factors and food insecurity. Biological sex and social gender are multi-dimensional, non-binary concepts that provide unique measurement challenges (Bauer et al., 2017). Multiple question formats have been recommended to better reflect the diversity of sex and gender characteristics and their relationships to health (Bauer et al., 2017; Tate et al., 2013). Finally, we used a volunteer sample which was comparable to the undergraduate campus population with respect to gender, living on campus, and proportion of Aboriginal and international students. Nevertheless, we cannot rule out a response bias.

\section{Conclusions}

This study provides further support for concerns about high levels of food insecurity among university students in Canada and the risk for physical, emotional and social impacts. Our findings show this is particularly true for individuals who are already vulnerable to socio-economic inequity due to belonging to marginalized groups. More research must be done to investigate the nature and experience of student food insecurity. Systemic social and economic factors must be addressed to reduce inequities experienced by those who experience marginalization. Efforts to promote student well-being on university campuses need to address food insecurity by addressing system-level factors to equalize the field for all students at risk for food insecurity.

\section{References}

Bauer, G. R., Braimoh, J., Scheim, A. I., \& Dharma, C. (2017). Transgender-inclusive measures of sex/ gender for population surveys: Mixed-methods evaluation and recommendations. PloS one, 12(5), e0178043. https://doi.org/10.1371/journal. pone. 0178043

Billings, D., \& Cabbil, L. (2011). Food justice: What's race got to do with it? Race/Ethnicity: Multidisciplinary Global Contexts, 5(1), 103-112. https://doi. org/10.2979/racethmulglocon.5.1.103

Blundell, L., Mathews, M., Bowley, C., \& Roebothan, B. (2018). Determining student food insecurity at memorial university of Newfoundland. Canadian Journal of Dietetic Practice and Research, 80(1), 14-21. https://doi.org/10.3148/cjdpr-2018-026

Broton, K. M., Weaver, K. E., \& Mai, M. (2018). Hunger in higher education: Experiences and correlates of food insecurity among Wisconsin undergraduates from low-income families. Social Sciences, 7(10), 179. https://doi.org/10.3390/socsci7100179

Brown, T. N., Romero, A. P., \& Gates, G. J. (2016). Food insecurity and SNAP participation in the LGBT community. https://williamsinstitute.law.ucla.edul wp-content/uploads/Food-Insecurity-and-SNAP-Participation-in-the-LGBT-Community.pdf

Brucker, D. L. (2016). Food security among young adults with disabilities in the United States: Findings from the National Health Interview Survey. Disability and Health Journal, 9(2), 298-305. https://doi. org/10.1016/j.dhjo.2015.10.003

Bruening, M., Argo, K., Payne-Sturges, D., \& Laska, M. N. (2017). The struggle is real: A systematic review of food insecurity on postsecondary education campuses. Journal of the Academy of Nutrition and Dietetics, 117(11), 1767-1791. https://doi. 


\section{org/10.1016/j.jand.2017.05.022}

Entz, M., Slater, J., \& Desmarais, A. A. (2017). Student food insecurity at the University of Manitoba. Canadian Food Studies/La Revue Canadienne Des Études Sur L'Alimentation, 4(1), 139-159. https:ll doi.org/10.15353/cfs-rcea.v4i1.204

Farahbakhsh, J., Hanbazaza, M., Ball, G. D. C., Farmer, A. P., Maximova, K., \& Willows, N. D. (2017). Food insecure student clients of a university-based food bank have compromised health, dietary intake and academic quality. Nutrition and Dietetics, 74(1), 67-73. https://doi.org/10.1111/1747-0080.12307

Frank, L. (2018). "Hungry for an education": Prevalence and outcomes of food insecurity among students at a primarily undergraduate university in rural Nova Scotia. Canadian Journal of Higher Education, 48(2), 109-129. https://doi.org/10.7202/1057106ar

Government of Canada. (2012a). Household food insecurity in Canada: Overview. https://www. canada.ca/en/health-canada/services/food-nutrition/ food-nutrition-surveillance/health-nutrition-surveys/ canadian-community-health-survey-cchs/household-food-insecurity-canada-overview.html

Government of Canada. (2012b). The household food security survey module (HFSSM). https://www. canada.ca/en/health-canada/services/food-nutrition/ food-nutrition-surveillance/health-nutrition-surveys/canadian-community-health-survey-cchs/ household-food-insecurity-canada-overview/household-food-security-survey-module-hfssm-health-nutrition-surveys-health-canada.html

Hanbazaza, M., Ball, G. D., Farmer, A. P., Maximova, K., Farahbakhsh, J., \& Willows, N. D. (2017). A comparison of characteristics and food insecurity coping strategies between international and domestic postsecondary students using a food bank located on a university campus. Canadian Journal of Dietetic Practice and Research, 78(4), 208-211. https://doi. org/10.3148/cjdpr-2017-012

Hattangadi, N., Vogel, E., Carroll, L. J., \& Côté, P. (2019). "Everybody I know is always hungry... but nobody asks why": University students, food insecurity and mental health. Sustainability, 11(6), 1571. https://doi.org/10.3390/su11061571
Maroto, M. E., Snelling, A., \& Linck, H. (2015). Food insecurity among community college students: Prevalence and association with grade point average. Community College Journal of Research and Practice, 39(6), 515-526. https://doi.org/10.1080/10 $\underline{668926.2013 .850758}$

Maynard, M. S., Meyer, S. B., Perlman, C. M., \& Kirkpatrick, S. I. (2018). Experiences of food insecurity among undergraduate students: "You can't starve yourself through school". Canadian Journal of Higher Education, 48(2), 130-148. https://doi. org/10.7202/1057107ar

Meza, A., Altman, E., Martinez, S., \& Leung, C. W. (2019). "It's a feeling that one is not worth food": A qualitative study exploring the psychosocial experience and academic consequences of food insecurity among college students. Journal of the Academy of Nutrition and Dietetics, 119(10), 1713-1721. https://doi.org/10.1016/j.jand.2018.09.006

Research to Identify Policy Options to Reduce Food Insecurity (PROOF). (2018). Household food insecurity in Canada. A guide to measurement and interpretation. https://proof.utoronto.ca/wp-content/ uploads/2018/11/Household-Food-Insecurity-in-Canada-A-Guide-to-Measurement-and-Interpretation.pdf

Reynolds, E., Johnson, C., Jamieson, J. A., \& Mawhinney, H. (2018). Prevalence and correlates of food insecurity among students attending a small, rural Canadian university. Canadian Journal of Dietetic Practice and Research, 79(3), 125-128. https://doi. org/10.3148/cjdpr-2018-004

Silva, M. R., Kleinert, W. L., Sheppard, A. V., Cantrell, K. A., Freeman-Coppadge, D. J., Tsoy, E., Roberts, T., \& Pearrow, M. (2017). The relationship between food security, housing stability, and school performance among college students in an urban university. Journal of College Student Retention: Research, Theory \& Practice, 19(3), 284-299. https://doi. org/10.1177/1521025115621918

Silverthorn, D. (2016). Hungry for knowledge: Assessing the prevalence of food insecurity on five Canadian campuses. Meal Exchange. https://www.mealexchange.com/

Spaid, R., \& Gillett-Karam, R. (2018). Food for thought: 
Food insecurity in women attending community colleges. Forum on Public Policy, 1. http://forumonpublicpolicy.com/wp-content/uploads/2017/10/ Spaid-and-Gillett.pdf

Steinprinz, G. (2017). From disability to diversability. In S. Dzigurski (Ed.), Europe in transition: Diversity, identity and youth work (pp. 27-30). SALTO Cultural Diversity Resource Centre. https://www.salto-youth. net/downloads/4-17-3716/EuropelnTransition.pdf

Tate, C. C., Ledbetter, J. N., \& Youssef, C. P. (2013). A two-question method for assessing gender categories in the social and medical sciences. Journal of Sex Research, 50(8), 767-776. https://doi.org/10.10 80/00224499.2012.690110

Tarasuk, V., Mitchell, A., \& Dachner, N. (2016). Household food insecurity in Canada, 2014. https://proof. utoronto.ca/wp-content/uploads/2016/04/Household-Food-Insecurity-in-Canada-2014.pdf

Tate, C. C., Ledbetter, J. N., \& Youssef, C. P. (2013). A two-question method for assessing gender categories in the social and medical sciences. Journal of Sex Research, 50(8), 767-776. https://doi.org/10.10 80/00224499.2012.690110

van Woerden, I. (2019). Food insecure college students and objective measurements of their unused meal plans. Nutrients, 11(4), 904. https://doi.org/10.3390/ $\underline{\text { nu11040904 }}$

Zuercher, J. L., \& Lutz, N. (2018). Food security and the on-campus student: Assessment of meal plan use. Journal of Nutrition Education and Behavior, 50(7), S124. https://doi.org/10.1016/j.jneb.2018.04.175

\section{Contact Information}

Joan L. Bottorff

joan.bottorff@ubc.ca 